\title{
Articles
}

\section{Isolated post-challenge hyperglycaemia confirmed as a risk factor for mortality}

\author{
J.E. Shaw ${ }^{1}$, A.M. Hodge ${ }^{1}$, M. de Courten ${ }^{1}$, P. Chitson ${ }^{2}$, P.Z. Zimmet ${ }^{1}$ \\ ${ }^{1}$ International Diabetes Institute, Melbourne, Australia \\ ${ }^{2}$ Ministry of Health, Port Louis, Mauritius
}

\section{Abstract}

Aims/hypothesis. The aim of this study was to examine the possible link between isolated post-challenge hyperglycaemia (2-h post-challenge plasma glucose $\geq 11.1 \mathrm{mmol} / \mathrm{l}$, and fasting plasma glucose $<7.0 \mathrm{mmol} / \mathrm{l}$ ) and mortality.

Methods. The data from three population based longitudinal studies (in Mauritius, Fiji and Nauru) were pooled and mortality rates were determined in 9179 people who were followed for between 5 and 12 years. Results. There were 595 people with previously diagnosed diabetes, and 799 with newly diagnosed diabetes, of whom 243 (31) had isolated post-challenge hyperglycaemia. In comparison with people without diabetes, people with isolated post-challenge hyperglycaemia had an increased risk of all-cause mortality
[Cox proportional hazards ratio $(95 \%$ CI): 2.7 (1.8-3.9) - men; 2.0 (1.3-3.3) - women], and of cardiovascular mortality $[2.3(1.2-4.2)$ - men; 2.6 (1.3-5.1) - women]. In addition, men with isolated post-challenge hyperglycaemia had a high risk of cancer death [8.0 (3.6-17.9)].

Conclusion/interpretation. These data show that isolated post-challenge hyperglycaemia, which can only be identified by the 2-h glucose, is common, and at least doubles the mortality risk. This should be considered in the design of screening programmes that use only fasting glucose [Diabetologia (1999) 42: 1050-1054]

Keywords Type II diabetes, mortality, cardiovascular disease, cancer, population study, post-challenge hyperglycaemia.
The oral glucose tolerance test (OGTT) identifies a proportion of people who have a diabetic post-challenge blood glucose, but a non-diabetic fasting value. The prevalence of isolated post-challenge hyperglycaemia (IPH) is variable but has been reported to account for as much as $70 \%$ of all undiagnosed diabetes

Received: 18 March 1999 and in revised form: 27 May 1999

Corresponding author: Dr M. de Courten,International Diabetes Institute, 260 Kooyong Road,Caulfield, Victoria, 3162 Australia

Abbreviations: IPH, Isolated post-challenge hyperglycaemia; ADA, American Diabetes Association; FPG, fasting plasma glucose; 2h-PG, 2-h plasma glucose; IFH, isolated fasting hyperglycaemia; $\mathrm{CH}$, combined hyperglycaemia; KDM, known diabetes; WHO, World Health Organization; ICD, International Classification of diseases; CVD, cardiovascular disease. in elderly women [1] and is also common amongst the non-obese [2].

The clinical significance of IPH has not been fully explored but it is particularly relevant now since the American Diabetes Association (ADA) Expert Committee has recommended that fasting glucose alone be used in both clinical and epidemiological settings to diagnose diabetes [3]. In the Rancho Bernardo study [1], elderly women with IPH had a significantly raised risk of fatal cardiovascular disease compared with non-diabetic women. If data from other populations confirm that IPH is common and is an independent risk factor for diabetes-related end-points, then this would suggest that the post-challenge glucose concentration provides valuable information that is additional to that provided by the fasting glucose.

We report here on the relation between IPH (as well as other categories of diabetes) and mortality us- 
Table 1. Baseline characteristics, follow-up and mortality in the three different surveys

\begin{tabular}{|c|c|c|c|c|c|c|}
\hline & $\begin{array}{l}\text { Total } \\
\text { population }\end{array}$ & $\begin{array}{l}\text { Age } \\
\text { (years) }\end{array}$ & $\begin{array}{l}\text { Total } \\
\text { diabetes }^{\mathrm{a}}\end{array}$ & IPH & $\begin{array}{l}\text { Median } \\
\text { follow up } \\
\text { (years) }\end{array}$ & Deaths \\
\hline Mauritius & 5057 & $43 \pm 13$ & $694(14.0)$ & $151(3.1)$ & 5.0 & $219(4.3)$ \\
\hline Nauru & 1576 & $36 \pm 13$ & $405(25.7)$ & $33(2.0)$ & 12.4 & $325(20.6)$ \\
\hline
\end{tabular}

Data are $n(\%)$, means \pm SD, and medians.

${ }^{a}$ Includes previously and newly diagnosed

ing data from three longitudinal population based studies.

\section{Subjects and methods}

The populations studied were in Mauritius, an Indian Ocean island, Fiji and Nauru (both in the Pacific). In Mauritius, approximately $70 \%$ of the population is of Asian Indian origin, $2 \%$ Chinese and $28 \%$ "general population" who are predominantly people of African ancestry (Creoles) with varying European, Malagasy and Indian admixture. In Fiji, the population is of Indian (49\%) and Melanesian (46\%) origin, and the Nauruan population is over $90 \%$ Micronesian. The Mauritian survey included adults aged 25-74 years, and the other two surveys included all adults aged 20 years and above. In all three surveys, over $90 \%$ of participants were under the age of 65 . Each of the surveys was population based and had a response rate of over $80 \%$.

Each of the three baseline surveys was done in a similar manner, and detailed descriptions have been published previously [4-6]. Briefly, all eligible adults were asked to attend a survey site between 0800 and 1000, after an overnight fast. Following registration, all participants had fasting blood samples taken and all, except those on treatment for diabetes, had an OGTT (75 g dextrose monohydrate in $250 \mathrm{ml}$ water). Fasting and 2-h plasma glucose concentrations were determined immediately on site with a YSI glucose analyser (Yellow Springs, Ohio, USA). For this analysis, classifications of diabetes were based on the recent American Diabetes Association recommendations [3]. IPH was defined as fasting plasma glucose $(\mathrm{FPG})<7.0 \mathrm{mmol} / \mathrm{l}$ and 2 -h plasma glucose $(2 \mathrm{~h}-$ $\mathrm{PG}) \geq 11.1 \mathrm{mmol} / \mathrm{l}$. Isolated fasting hyperglycaemia (IFH) was defined as FPG $\geq 7.0 \mathrm{mmol} / \mathrm{l}$ and $2 \mathrm{~h}-\mathrm{PG}<11.1 \mathrm{mmol} / \mathrm{l}$. Combined hyperglycaemia $(\mathrm{CH})$ was defined as $\mathrm{FPG} \geq 7.0 \mathrm{mmol} / \mathrm{l}$ and $2 \mathrm{~h}-\mathrm{PG} \geq 11.1 \mathrm{mmol} / \mathrm{l}$. Those with a history of diabetes were classified as known diabetes (KDM), and the non-diabetic population (FPG $<7.0 \mathrm{mmol} / \mathrm{l}$ and $2 \mathrm{~h}-\mathrm{PG}<11.1 \mathrm{mmol} / \mathrm{l})$ served as the reference population.

Blood pressure was measured after a 5 min rest, with the participant sitting, using the first and fifth Korotkoff sounds recorded to the nearest $2 \mathrm{mmHg}$. Blood pressure was recorded twice, and the mean value was used. Hypertension was diagnosed on the basis of World Health Organization (WHO) criteria (systolic blood pressure $\geq 160 \mathrm{mmHg}$ and/or diastolic blood pressure $\geq 95 \mathrm{mmHg}$ ) or of self reported antihypertensive medication taken in the past week. Height and weight were measured in light clothing without shoes, and the body mass index $(\mathrm{BMI})$ was calculated as weight $(\mathrm{kg}) /$ height $(\mathrm{m})^{2}$.

Information on mortality was collected from death certificates in each country and coded according to the International Classification of Diseases (ICD) ninth revision codes [7]. ICD codes 401-414 and 426-444 were used for cardiovascular dis- ease (CVD) deaths, and 140-239 for cancer deaths. In Nauru, the baseline survey was done in 1982, and the vital status of all 1576 survey participants was determined in 1994. During this period, all death certificates for the island were examined. The baseline survey in Fiji was done in 1980, and follow-up until 1991 was carried out by a specially trained nurse doing house-to-house visits and regular surveillance of medical records. Death certificates of those reported to have died were traced, and in 1991, vital status was known for $96.5 \%$ of the cohort. The baseline survey in Mauritius was done in 1987. Vital status was determined by household interviews in 1989 and 1992 for $99.5 \%$ of the 1987 cohort. Death certificates were traced for those reported to have died.

Statistical analysis. Statistical analysis was done with SPSS 8.0 software (SPSS, Inc., Ill., USA). The data from the three surveys were pooled and analysed as a single cohort. Mortality percentages from each glucose category were age-standardized to the whole study population by the direct method. The Cox proportional hazards model was used to determine the mortality risk associated with each category of diabetes. Potential confounders were forced into the models, unless stated otherwise in the text.

\section{Results}

At baseline, there were 9297 participants (5083 from Mauritius, 2638 from Fiji, 1576 from Nauru), and vital status was available in $9179(98.7 \%)$ at follow-up (Table 1). At baseline, there were 243 people with IPH representing $31 \%$ (30\% for men, $32 \%$ for women) of the newly diagnosed diabetic population and $18 \%$ ( $17 \%$ for men, $18 \%$ for women) of the total diabetic population.

The median follow-up for survivors was 5.0 years, and there were 848 deaths. Table 2 shows the number of deaths in each category of diabetes for all causes as well as for CVD and cancer. Amongst the 1379 people with diabetes at baseline, there were 370 deaths of which 140 were due to CVD, 85 were attributed directly to diabetes, and 39 to cancer. Amongst those with IPH at baseline there were 50 deaths accounting for $5.9 \%$ of all deaths and $13.5 \%$ of deaths amongst people with diabetes at baseline.

For the 243 people with IPH, the median (interquartile range) FPG was $6.0(5.4-6.4) \mathrm{mmol} / \mathrm{l}$, and for the 50 IPH people who died it was $5.7(5.0-6.3) \mathrm{mmol} / \mathrm{l}$.

Table 3 and Figure 1 show the mortality risk for the different categories of diabetes as determined by 
A

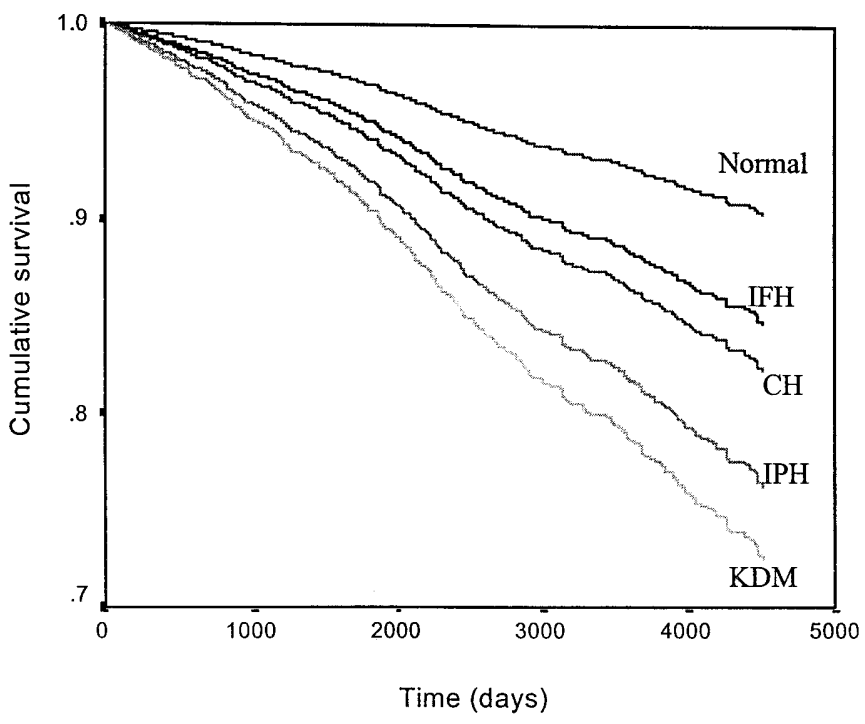

B

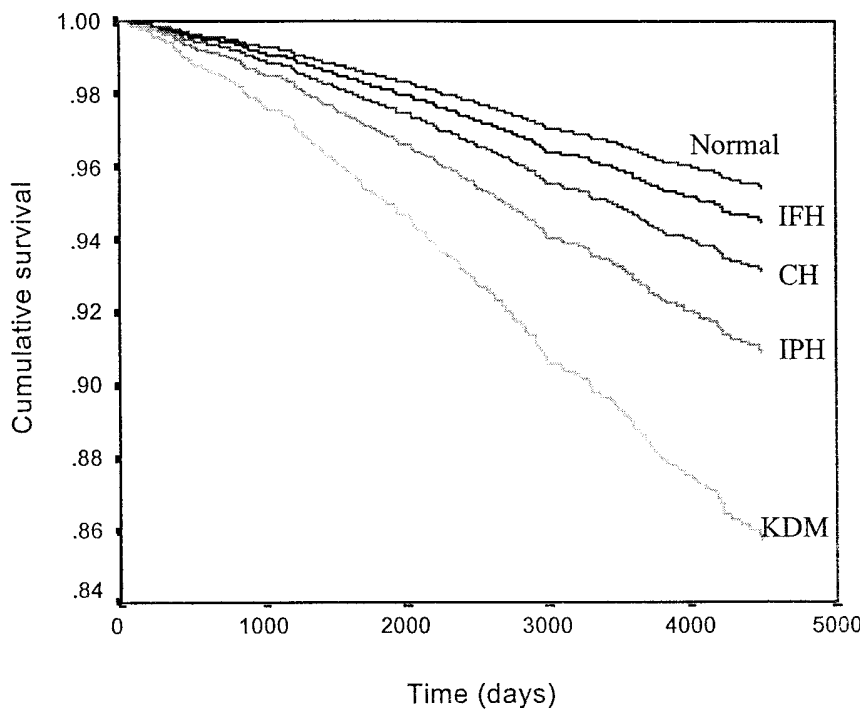

Fig. 1. Adjusted survival (Cox proportional hazards all cause mortality adjusted for age and ethnicity), according to diabetes category for $\mathbf{A}$ men, and B Women

the Cox proportional hazards model. All cause mortality was significantly increased relative to the nondiabetic population for IPH, CH and KDM, though not for IFH. Similar results were seen for cardiovascular deaths, although amongst women with $\mathrm{CH}$ the excess risk only became significant (hazards ratio $1.8, p=0.049)$ when smoking and ethnicity were removed from the model. [Neither smoking $(p=0.18)$ nor ethnicity $(p=0.63)$ were associated with cardiovascular mortality in women.] The greatest risk observed in these models was for cancer in men with IPH. There were nine cancer deaths out of 110 men with IPH, producing a hazards ratio of 8.0 $(p<0.0001)$, which was not altered when adjusting
Table 2. Mortality according to diabetes category and sex

\begin{tabular}{lrrrr}
\hline & $n$ & All deaths & CVD deaths & $\begin{array}{l}\text { Cancer } \\
\text { deaths }\end{array}$ \\
\hline Men & & & & \\
Non-diabetic & 3606 & $289(9.0)$ & $127(4.1)$ & $23(0.7)$ \\
IPH & 110 & $30(16.2)$ & $11(6.0)$ & $9(4.4)$ \\
IFH & 76 & $13(16.4)$ & $4(4.3)$ & $0(0.0)$ \\
CH & 183 & $51(20.6)$ & $20(7.5)$ & $6(1.7)$ \\
KDM & 278 & $122(39.5)$ & $48(12.0)$ & $5(0.9)$ \\
Women & & & & \\
Non-diabetic & 4170 & $183(5.0)$ & $70(2.0)$ & $35(0.9)$ \\
IPH & 133 & $20(9.5)$ & $10(4.7)$ & $4(1.5)$ \\
IFH & 66 & $8(11.4)$ & $4(4.9)$ & $1(2.3)$ \\
CH & 221 & $29(10.0)$ & $13(3.9)$ & $4(1.2)$ \\
KDM & 317 & $97(25.8)$ & $30(4.8)$ & $10(3.1)$ \\
\hline
\end{tabular}

Data are numbers (\%).

Percentages are age-standardized to the whole study population by the direct method

Table 3. The mortality risk (Cox proportional relative hazards) in different diabetes categories

\begin{tabular}{|c|c|c|c|}
\hline Adjusted for & $\begin{array}{l}\text { All cause } \\
\text { Age, ethnicity }\end{array}$ & $\begin{array}{l}\text { CVD } \\
\text { Age, ethnicity, } \\
\text { smoking, } \\
\text { blood pressure, } \\
\text { BMI }\end{array}$ & $\begin{array}{l}\text { Cancer } \\
\text { Age, ethnicity, } \\
\text { smoking }\end{array}$ \\
\hline \multicolumn{4}{|l|}{ Men } \\
\hline Non-diabetic & 1.0 & 1.0 & 1.0 \\
\hline IPH & $2.7(1.8-3.9)^{\mathrm{a}}$ & $2.3(1.2-4.2)^{\mathrm{c}}$ & $8.0(3.6-17.9)^{\mathrm{a}}$ \\
\hline IFH & $1.6(0.9-2.9)$ & $1.3(0.5-3.6)$ & \\
\hline $\mathrm{CH}$ & $1.9(1.4-2.6)^{\mathrm{a}}$ & $1.7(1.0-2.8)^{\mathrm{c}}$ & $2.5(1.0-6.5)$ \\
\hline KDM & $3.2(2.5-4.0)^{\mathrm{a}}$ & $3.0(2.1-4.3)^{\mathrm{a}}$ & $1.1(0.4-3.6)$ \\
\hline \multicolumn{4}{|l|}{ Women } \\
\hline Non-diabetic & 1.0 & 1.0 & 1.0 \\
\hline IPH & $2.0(1.3-3.3)^{\mathrm{b}}$ & $2.6(1.3-5.1)^{\mathrm{b}}$ & $2.2(0.8-6.5)$ \\
\hline IFH & $1.2(0.6-2.6)$ & $1.4(0.5-4.0)$ & $0.9(0.1-6.8)$ \\
\hline $\mathrm{CH}$ & $1.5(1.0-2.3)^{\mathrm{c}}$ & $1.7(0.9-3.2)$ & $1.0(0.3-2.9)$ \\
\hline KDM & $3.3(2.5-4.3)^{\mathrm{a}}$ & $2.9(1.9-4.6)^{\mathrm{a}}$ & $1.5(0.7-3.4)$ \\
\hline
\end{tabular}

Data are relative hazards ( $95 \%$ confidence intervals).

${ }^{\mathrm{a}} p<0.0001,{ }^{\mathrm{b}} p<0.01,{ }^{\mathrm{c}} p<0.05$

for baseline BMI or when deaths due to pancreatic cancer were removed. The hazards ratio for cancer deaths amongst women with IPH was 2.2 but this was not significant $(p=0.13)$. Amongst men with $\mathrm{CH}$, the hazards ratio for cancer was also high at 2.5, but this also was not significant $(p=0.06)$. The excess risk for cancer death, however, became significant in these men (hazards ratio 2.9, $p=0.02$ ), when smoking and ethnicity were removed from the model. [Neither smoking $(p=0.19)$ nor ethnicity $(p=0.14)$ were strongly associated with cancer mortality in men.]

\section{Discussion}

The excess of cardiovascular disease and increased mortality rates in Type II diabetes have been shown in a wide range of studies [8-11]. To prevent these 
outcomes screening for and aggressive management of Type II diabetes is promoted [3]. Data from the UKPDS now indicate that the latter may be successful $[12,13]$. If screening concentrates on the fasting state only, as recommended by the ADA [3), then people whose only abnormality is in the post-load state will be missed. Such people are common [2], especially amongst elderly populations [1]. What has not been clear is how important IPH is. Recently, IPH was found to be a major risk factor for cardiovascular death in elderly women in one study [1] and for death from any cause in men aged 60-79 [14].

We have now shown that in a mixed population of Asian Indians, Pacific Islanders and people of African origin followed over 5-12 years, IPH was a strong predictor of mortality in both men and women. The data in Table 3 are adjusted for ethnicity and survey site and hence account for differences between the three populations. In addition, when the three populations were analysed separately (data not shown), IPH remained a risk factor for total mortality (significant for Mauritius and Fiji) and cardiovascular mortality (significant for Fiji). The risk of all cause and cardiovascular mortality was at least as strong for IPH as it was for those with abnormalities in both the fasting and post-load state $(\mathrm{CH})$ and only slightly lower than the risk in previously diagnosed diabetes, although the width of the confidence intervals precludes accurate ranking. Note that there was no significant risk associated with IFH. This is possibly partly due to its relative infrequency in this cohort but is consistent with a recent study of elderly Americans [15] in which the prevalence of cardiovascular disease was similar in normoglycaemic people and those with IFH (24\% vs $22 \%)$ and higher in people with IPH $(31 \%)$. In the Hoorn study, however, people with IFH had abnormal blood pressure and lipids [16], and in two other cohorts, after 20 years of follow-up, excess mortality was shown in men with IFH [17].

A surprising result was the strong risk of cancer death in men (and perhaps also women) with IPH. Conflicting results have previously been reported on the possible link between diabetes and cancer. In a 12-year study of 20000 men and women in Chicago [18], a high blood glucose $1 \mathrm{~h}$ after a $50 \mathrm{~g}$ glucose challenge was a risk factor for cancer death, but known diabetes was not. Some studies have also reported that diabetes is a risk factor for cancer death $[17,19$, 20], but in an analysis of more than 18000 men from the Whitehall study over 18 years [21] neither hyperglycaemia nor known diabetes were risk factors for cancer death, except from pancreatic cancer. Other prospective studies have also failed to find a link between diabetes and cancer [22-24]. If, as our data suggest, the risk of cancer is concentrated in those people with IPH then the variability of the prevalence of IPH, and failure to analyse this group separately from other people with diabetes would be expected to produce varying results in different studies.

There is no obvious explanation for the association of IPH with cancer, and the relatively small number of events precludes analysis by type of cancer. Isolated post-challenge hyperglycaemia is more common in lean rather than obese people and might simply be a marker for weight loss. Indeed, in our study, the baseline BMI was lower (though not significantly) in those IPH men who died of cancer than in either those who survived or those who died of CVD. The association between IPH and cancer death, however, remained after adjusting for BMI and after excluding deaths in the first 2 years of follow-up (data not shown), suggesting that IPH is not just a marker for weight loss.

The accuracy of death certificates in describing the true cause of death is known to be limited and this may partly explain the high proportion of deaths that were attributed directly to diabetes. Whilst this possibly affects the confidence in the associations that we have reported with specific causes of death, the high total mortality in IPH remains a sound and important finding.

In summary, our study, like the two previous studies $[1,14]$, shows that IPH is a common form of diabetes and increases mortality in magnitude similar to that of other forms of diabetes. By definition, people with IPH would not be classified as being diabetic by their fasting glucose and over $50 \%$ of them would not even be classified as having impaired fasting glucose. Thus, the OGTT would be the only way to identify their real hyperglycaemic risk. We believe and recommend that the OGTT still has an important part to play in identifying those people at risk of diabetes related complications, especially the elderly in whom IPH is common.

Acknowledgements. This study was undertaken with the support and collaboration of the Ministry of Health (Mauritius) and the World Health Organization (Geneva and Mauritius). The study was partially supported by the United States National Institutes of Health Grant DK-25446. J.E. Shaw is supported by a grant from the Institute for Diabetes Discovery, Connecticut, USA.

\section{References}

1. Barrett-Connor E, Ferrarra A (1998) Isolated postchallenge hyperglycemia and the risk of fatal cardiovascular disease in older women and men. Diabetes Care 21: 1236-1239

2. DECODE Study Group (1998) Will new diagnostic criteria for diabetes mellitus change phenotype of patients with diabetes? Reanalysis of European epidemiological data. BMJ 317: 371-375

3. American Diabetes Association (1997) Report of the expert committee on the diagnosis and classification of diabetes mellitus. Diabetes Care 20: 1183-1197 
4. Dowse GK, Gareeboo H, Zimmet Pz et al. (1990) High prevalence of NIDDM and impaired glucose tolerance in Indian Creole and Chinese Mauritians. Diabetes 39: 390-396

5. Zimmet P, Taylor R, Ram P et al. (1983) The prevalence of diabetes and impaired glucose tolerance in the biracial (Melanesian and Indian) population of Fiji:a rural-urban comparison. Am J Epidemiol 118: 673-688

6. Zimmet P, King H, Taylor R et al. (1984) The high prevalence of diabetes mellitus, impaired glucose tolerance and diabetic retinopathy in Nauru - the 1982 survey. Diabetes Res 1: 13-18

7. World Health Organization (1977) The manual of the international statistical classification of diseases, injuries and causes of death (ninth revision). WHO, Geneva

8. Jarrett RJ, McCartney P, Keen H (1982) The Bedford Survey:ten-year mortality rates in newly diagnosed diabetics, borderline diabetics and normoglycaemic controls and risk indices for coronary heart disease in borderline diabetics. Diabetologia 22: 79-84

9. Sasaki A, Uehera M, Horiuchi M, Hasagawa K (1983) A long term follow-up study of Japanese diabetic patients:mortality and causes of death. Diabetologia 25: 309-312

10. Uusitupa MIJ, Niskanen LK, Siitonen O, Voutilainen E, Pyorala K (1993) Ten-year cardiovascular mortality in relation to risk factors and abnormalities in lipoprotein composition in type 2 (non-insulin dependent) diabetic and nondiabetic subjects. Diabetologia 36: 1175-1184

11. Moss SE, Klein R, Klein BE (1991) Cause-specific mortality in a population-based study of diabetes. Am J Public Health 81: 1158-1162

12. UK Prospective Diabetes Study Group (1998) Intensive blood glucose control with sulphonylureas or insulin compared with conventional treatment and risk of complications in patients with type 2 diabetes (UKPDS 33). Lancet 352: 837-853

13. UK Prospective Diabetes Study Group (1998) Effect of intensive blood glucose control with metformin on complications in overweight patients with type 2 diabetes (UKPDS 34). Lancet 352: 854-865
14. Balkau B (1999) New diagnostic criteria for diabetes and mortality in older adults. Lancet 353: 68-69

15. Wahl PW, Savage PJ, Psaty BM, Orchard TJ, Robbins JA, Tracey RP (1998) Diabetes in older adults:comparison of 1997 American Diabetes Association classification of diabetes mellitus with 1985 WHO classification. Lancet 352: 1012-1015

16. De Vegt F, Dekker JM, Stehouwer CDA, Nijpels G, Bouter LM, Heine RJ (1998) The 1997 American Diabetes Association criteria versus the 1985 World Health Organization criteria for the diagnosis of abnormal glucose tolerance. Diabetes Care 21: 1686-1690

17. Balkau B, Shipley M, Jarrett RJ et al. (1998) High blood glucose concentration is a risk factor for mortality in middle-aged nondiabetic men, Diabetes Care 21: 360-367

18. Levine W, Dyer AR, Shekelle RB, Schoenberger JA, Stamler J (1990) Post-load plasma glucose and cancer mortality in middle-aged men and women. 12-year follow-up findings of the Chicago Heart Association Detection Project in Industry. Am J Epidemiol 131: 254-262

19. Koskinen SV, Reunanen AR, Martelin TP, Valkonen T (1998) Mortality in a large population-based cohort of patients with drug-treated diabetes mellitus. Am J Public Health 88: 765-770

20. Yano K, Kagan A, McGee D, Rhoads GG (1982) Glucose intolerance and nine-year mortality in Japanese men in Hawaii. Am J Med 72: 71-80

21. Smith GD, Egger M, Shipley MJ, Marmot MG (1992) Postchallenge glucose concentration, impaired glucose tolerance, diabetes, and cancer mortality in men. Am J Epidemiol 136: 1110-1114

22. Stengard JH, Tuomilehto J, Pekkanen J et al. (1992) Diabetes mellitus, impaired glucose tolerance and mortality among elderly men:the Finnish cohorts of the Seven Countries Study. Diabetologia 35: 760-765

23. Adlerberth AM, Rosengren A, Wilhelmsen L (1998) Diabetes and long-term risk of mortality from coronary and other causes in middle-aged Swedish men. A general population study. Diabetes Care 21: 539-545

24. Moss SE, Klein R, Klein BE, Meuer SM (1994) The association of glycemia and cause-specific mortality in a diabetic population. Arch Intern Med 154: 2473-2479 